\title{
Applying QCA with Fuzzy Logic to Generate a Refined set of Factors for Information Systems Adoption: The Case of Public Ecuadorian Organization, an Example of IS Adoption in Emerging Economies
}

\author{
https://doi.org/10.3991/ijoe.v15i03.9833 \\ Nayeth I. Solorzano Alcivar $(\llbracket)$ \\ ESPOL Polytechnic University, Guayaquil, Ecuador \\ nsolorza@espol.edu.ec \\ Louis Sanzogni, Luke Houghton \\ Griffith University, Brisbane, Australia
}

\begin{abstract}
Information Systems (IS) research continues to contribute to a long list of technology adoption factors from many studies conducted outside the Latin American (LAT) nations. These investigations fail to appropriate the context of IS adoption in LAT. This fail is mainly due to the geographical scope of existing studies. Those aimed at North America for example, are out of context regarding a diverse technological approach when applied to LAT. Further, uncertainty and an inability to predict outcomes of technology adoption, create variances in results because the local contexts are not considered. The reasons for this are unclear from existing studies. To detailed explore this problem further, a Qualitative Comparative Analysis (QCA) was applied to LAT economies, expecting to assess a refined set of drivers from existing technology adoption studies. A Fuzzy Logic process was used to refine these drivers. The research found that fourteen themes are candidates for future study purposes. The drivers provide LAT stakeholders, as well as actors from other emerging economies, with a contextual frame that can be the basis for adopting technology more meaningfully within these nations.
\end{abstract}

Keywords-Fuzzy-logic; Qualitative-Comparative-Analysis; $f_{s} / \mathrm{QCA}$; Information-System Adoption; Latin-America; Ecuador; Public Organization

\section{Introduction}

Predicting IS adoption outcomes in public organizations is challenging. Particularly in LAT economies where a scarcity of related technological studies is evident [1, 2]. The extraction of adoption factors from large sets of variables or extensive coding sets remains problematic given the pluralistic nature of adoption contexts. Single response categories (scales) might not completely capture perceptions [3, 4] related to the multifaceted technology adoption problem being studied in the local context. To 
this end, a Qualitative Comparative Analysis (QCA), applying fuzzy logic techniques, is used as a qualitative-quantitative bridging methodology to analyze predetermined sets of responses by examining necessary and/or sufficient related conditions [5] for adoption IS in LAT regions. Servant and Jones [6] for example, use fuzzy logic in historical analysis to improve revisions of larger code sets accurately. These authors also argued that a fuzzy technique is more precise than other methods, because it enables researchers to reduce large coding sets to more concisely defined ones.

QCA using fuzzy-set, complemented by a set of research tools, is an analytic approach that helps determine the necessary or sufficient conditions to evaluate significantly different outcomes of a selection process [5]. This technique is also useful for evaluating empirical analyses based on qualitative approaches [7]. QCA is used in this way to validate which of a large number of empirically refined factors, obtained from a previous study, should be selected as the most relevant for LAT nations. The unit of analysis in this study are Public Ecuadorian Organizations (PEOs). Studies often refer to different forms of QCA like crisp-set (csQCA) or fuzzy-set (fs/QCA) as opposed to multi-value form (mvQCA) to study necessary and/or sufficient conditions in data that have a complex set of variables and parameters [3, 4]. Servant and Jones [6], for example, use automatic code-history-analysis with a fuzzy history graph to expand the accuracy of a code history analysis, expecting to simplify the revision process of larger code line sets. These authors argue that this process is more accurate and consistent when attempting to determine finer coding grades in larger code sets [6].

In an early three-stage process, large sets of candidates IS adoption drivers were initially identified from hundreds of variables, factors, constructs, determinants, and categories proposed in existing IS/IT adoption theories, local secondary data, and the opinion of local experts/practitioners (see Fig 1). Even though a significant number of drivers were reduced to a more refined set using mixed-method analysis strategies, the obtained list remained excessively large to meet the requirement of this analysis. That is, to work towards a set of refined drivers suitable for future research towards a solution of complex adoption problems in LAT.

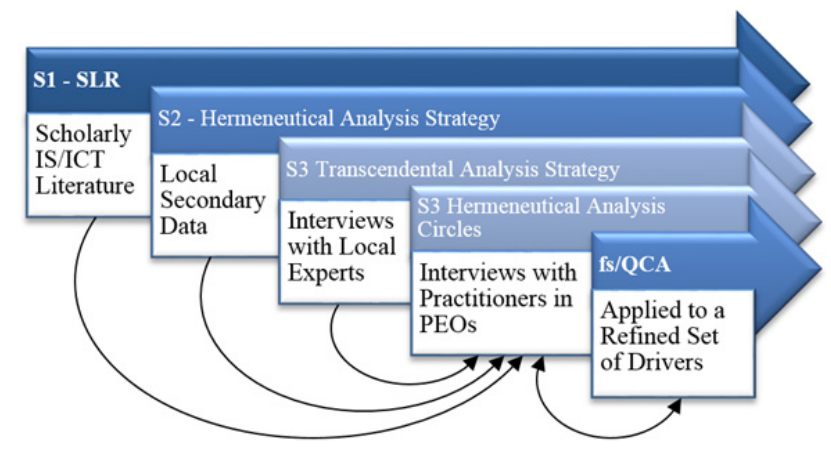

Fig. 1. The early three stages process of the bridged with $f_{s} / \mathrm{QCA}$ 
To provide a foundation for the analysis, a Systematic Literature Review was conducted. Primary data were collected using qualitative coding and NVivo (see Fig 1). To the data collection follows established principles of coding and data collection which is transparent, faster, and enables the researcher to categorize, classify and store data much more effectively [8]. The identified set of drivers also referred to as themes or candidate drivers, were not dichotomous imposing the need to use fs/QCA to refine the set and to perform causal relations analysis. The fs/QCA as a comparative analysis strategy was conducted to show associated patterning in the set of candidate factors in which each one was considered a "Case." Also, fs/QCA provides support for the existence of causal relations between determined conditions concerning the cases [7]. It is relevant to this study because it is a useful methodology for examining the underpinning theoretical concerns of existing models.

Therefore, the research question, "Which themes identified from existing IS/IT adoption theories, local secondary data, and local experts/practitioners' opinions, are the most prominent candidate drivers affecting SISA in LAT organizational contexts?" was expertly researched and justified. The results demonstrated a fine-grained categorization of themes and sets of similar characteristics could be explored in different LAT organizational contexts. These drivers can be anticipated for further IS adoption studies. The aim, therefore, is to produce a set of themes that other researchers can apply to similar local contexts to better understand the complexity of adoption in emerging economies.

\section{$2 \quad$ Applying Fuzzy QCA as a Bridging Methodology}

\subsection{The Scoring processes}

In this extensive mixed method study, guided by a pluralistic methodology from a pragmatic point of view [9-11], $f_{S} / \mathrm{QCA}$ was applied as a bridging process of a comparative analysis strategy for revealing association patterns of formed themes (as cases) and bringing support to identify causal relations between determined conditions related to the cases [7]. Fuzzy-set scores used by QCA are applied to normalize the Frequency of reference by Relevance (FrR) relationship of the 50 themes identified from the outcomes in three previous stages of this study (see Table 1). The FrR calculated ranges from 0.0000 to 0.1205 over 50 themes as the Maximum level of FrR per stage (see Table 1, columns FrR of Stages 1, Stage 2 and Stage 3).

According to Ragin [12], the fuzzy-set scores can be ranged from 0 to 1 to describe different case conditions in a set. In the $f_{S}$ /QCA process of this study, the 50 themes, previously identified from a set of drivers, are considered as the 'cases.' It is assumed that a set is a structured conceptual framework. In this research, cases are evaluated regarding FrR, obtained by each identified theme. From each of them, the relationship significance extracted from Literature analyzed of existing IS/IT adoption theories (Stage 1), local secondary data (Stage 2), local experts and practitioners' opinion transcripts (Stage 3) were qualitatively evaluated to saturation point $[13,14]$. Then the FrR was calculated in each stage (See Table 1 Section 1). 
Table 1. The initial set of themes as possible SISA drivers

\begin{tabular}{|c|c|c|c|c|c|c|c|c|c|c|c|c|c|c|c|c|c|c|}
\hline Sec Themes -candidate Drivers-(Caseid) & & NS FrR & & & FrR & $N R \quad N$ & NS & $\mathrm{FrR}$ & Cases: & 51 & $\frac{52}{52}+2,+2$ & s3 & LRT & LRTNS & STHR TH $\mathrm{C}$ ( $\mathrm{C}$ & THRS1 THRS2 & THPS3 & ST \\
\hline 1 Accessibility-Interconnectivity & 2 & 20.0032 & 99 & 16 & 0.0739 & 184 & 44 & 0.1109 & & 0.33 & 0.67 & 1 & 1 & 0.67 & 0.67 & & & 1 \\
\hline 2 Age & 7 & 70.0132 & & & & 49 & 26 & 0.0131 & & 0.33 & 0 & 0.33 & 0.33 & 0.33 & & & & \\
\hline 3 Attitude Towards Using-Intention to Use & 281 & 190.0575 & 45 & 12 & 0.0536 & 105 & 38 & 0.0390 & & 0.67 & 0.67 & 0.33 & 0.67 & 0.67 & 0.67 & & & 0.67 \\
\hline 4 Communication Channels & 12 & 70.0211 & 5 & 3 & 0.0040 & 53 & 25 & 0.0153 & & 0.33 & 0.33 & 0.33 & 0.33 & 0.33 & & & & \\
\hline 5 Compatibility \& Standardization & 6 & 60.0141 & 33 & 9 & 0.0234 & 70 & 28 & 0.0320 & & 0.33 & 0.33 & 0.33 & 0.33 & 0.33 & & & & \\
\hline 6 Corruption & 2 & 20.0055 & 3 & 2 & 0.0027 & 46 & 24 & 0.0137 & & 0.33 & 0.33 & 0.33 & 0.33 & 0.33 & & & & \\
\hline 7 Cultural \& Values Aspects & 25 & 40.0900 & 3 & 1 & 0.0027 & 54 & 32 & 0.0131 & & 1 & 0.33 & 0.33 & 1 & 0.33 & & 1 & & 1 \\
\hline 8 Defined Processes & 1 & 10.0011 & 4 & 3 & 0.0023 & 46 & 29 & 0.0170 & & 0.33 & 0.33 & 0.33 & 0.33 & 0.33 & & & & \\
\hline 9 Economic Aspects & 15 & 60.0399 & 3 & 2 & 0.0003 & 18 & 10 & 0.0012 & & 0.33 & 0.33 & 0.33 & 0.33 & 0.33 & & & & \\
\hline 10 Education \& Skills & 161 & 100.0355 & 47 & 16 & 0.0278 & 103 & 41 & 0.0345 & & 0.33 & 0.33 & 0.33 & 0.33 & 0.33 & & & & \\
\hline 11 Gender & 6 & 60.0043 & 1 & 1 & 0.0009 & 5 & 4 & 0.0003 & & 0.33 & 0.33 & 0.33 & 0.33 & 0.33 & & & & \\
\hline 12 Individual Income & 3 & 30.0066 & & & & 12 & 9 & 0.0020 & & 0.33 & 0 & 0.33 & 0.33 & 0.33 & & & & \\
\hline 13 Information Availability & & & 93 & 15 & 0.0948 & 93 & 32 & 0.0434 & & 0 & 1 & 0.67 & 1 & 0.67 & 0.67 & & & 1 \\
\hline 14 Information Quality & 6 & 60.0217 & 25 & 11 & 0.0303 & 44 & 27 & 0.0081 & & 0.33 & 0.33 & 0.33 & 0.33 & 0.33 & & & & \\
\hline 15 Intellectual Property and Software Rights (*) & & & 70 & 11 & 0.0630 & 49 & 20 & 0.0203 & & 0 & 0.67 & 0.33 & 0.67 & 0.33 & & 0.67 & & 0.67 \\
\hline 16 Internet Facilities & 5 & 50.0129 & 36 & 14 & 0.0320 & 71 & 31 & 0.0245 & & 0.33 & 0.33 & 0.33 & 0.33 & 0.33 & & & & \\
\hline 17 Job Relevance & 6 & 60.0099 & & - & & 5 & 2 & 0.0006 & & 0.33 & 0 & 0.33 & 0.33 & 0.33 & & & & \\
\hline 18 Labour Force & 2 & 20.0052 & & - & - & 24 & 16 & 0.0091 & & 0.33 & 0 & 0.33 & 0.33 & 0.33 & & & & \\
\hline 19 Language & 1 & 10.0030 & & - & - & 19 & 9 & 0.0017 & & 0.33 & 0 & 0.33 & 0.33 & 0.33 & & & & \\
\hline 20 Leadership Continuity & - - & & & - & & 26 & 13 & 0.0140 & & 0 & 0 & 0.33 & 0.33 & 0 & & & & \\
\hline 21 Loyalty & 2 & 20.0069 & & - & & 1 & 1 & & & 0.33 & 0 & 0 & 0.33 & 0 & & & & \\
\hline 22 Market Environment & 9 & 50.0218 & 5 & 3 & 0.0041 & 40 & 20 & 0.0092 & & 0.33 & 0.33 & 0.33 & 0.33 & 0.33 & & & & \\
\hline 23 National Plan-ICT Inclusion & - - & & 26 & 10 & 0.0259 & 24 & 12 & 0.0096 & & 0 & 0.33 & 0.33 & 0.33 & 0.33 & & & & \\
\hline 24 National Telecommunication Environment & 1 & 10.0013 & 4 & 1 & 0.0052 & 14 & 10 & 0.0021 & & 0.33 & 0.33 & 0.33 & 0.33 & 0.33 & & & & \\
\hline 25 Nature of Development & 4 & 30.0071 & 11 & 5 & 0.0122 & 106 & 29 & 0.0665 & & 0.33 & 0.33 & 0.67 & 0.67 & 0.33 & & & 0.67 & 0.67 \\
\hline 26 Net Benefits Perception & 11 & 100.0428 & 21 & 11 & 0.0244 & 49 & 21 & 0.0259 & & 0.67 & 0.33 & 0.33 & 0.67 & 0.33 & & 0.67 & & 0.67 \\
\hline 27 Observability & 3 & 30.0060 & & & & & 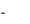 & & & 0.33 & 0 & 0 & 0.33 & 0 & & & & \\
\hline 28 Organisational Aspects & 12 & 80.0371 & 6 & 2 & 0.0063 & 3 & 3 & 0.0003 & & 0.33 & 0.33 & 0.33 & 0.33 & 0.33 & & & & \\
\hline 29 Organisational Experience \& Slack & 15 & 70.0331 & & & & 27 & 19 & 0.0030 & & 0.33 & 0 & 0.33 & 0.33 & 0.33 & & & & \\
\hline 30 Organisational Structure & 4 & 40.0061 & 33 & 5 & 0.0298 & 4 & 3 & 0.0001 & & 0.33 & 0.33 & 0.33 & 0.33 & 0.33 & & & & \\
\hline 31 Perceived Ease Of Use & 21 & 150.0577 & 5 & 3 & 0.0061 & 57 & 26 & 0.0184 & & 0.67 & 0.33 & 0.33 & 0.67 & 0.33 & & 0.67 & & 0.67 \\
\hline 32 Perceived Usefulness & 25 & 170.0778 & 52 & 13 & 0.0488 & 94 & 37 & 0.0436 & & 0.67 & 0.67 & 0.67 & 0.67 & 0.67 & 0.67 & & & 0.67 \\
\hline 33 Political Aspects & 7 & 60.0138 & 7 & 4 & 0.0053 & 83 & 25 & 0.0271 & & 0.33 & 0.33 & 0.33 & 0.33 & 0.33 & & & & \\
\hline 34 Population Changes & 1 & 10.0019 & - & - & & 1 & 1 & & & 0.33 & 0 & 0 & 0.33 & 0 & & & & \\
\hline 35 Regulation \& Policies (*) & 15 & 80.0346 & 129 & 19 & 0.1205 & 99 & 33 & 0.0429 & & 0.33 & 1 & 0.67 & 1 & 0.67 & 0.67 & & & 1 \\
\hline 36 Service Quality & 4 & 40.0149 & 23 & 10 & 0.0190 & 30 & 17 & 0.0099 & & 0.33 & 0.33 & 0.33 & 0.33 & 0.33 & & & & \\
\hline 37 Subjective Norms \& Motivation & 18 & 110.0581 & 3 & 2 & 0.0023 & 84 & 31 & 0.0228 & & 0.67 & 0.33 & 0.33 & 0.67 & 0.33 & & 0.67 & & 0.67 \\
\hline 38 System Characteristics & 9 & 60.0218 & 9 & 2 & 0.0123 & 33 & 16 & 0.0173 & & 0.33 & 0.33 & 0.33 & 0.33 & 0.33 & & & & \\
\hline $\begin{array}{l}39 \text { System Development \& Implementation } \\
\text { System Maintenance-Continuing }\end{array}$ & - - & - & 51 & 9 & 0.0545 & 53 & 23 & 0.0284 & & & 0.67 & 0.33 & 0.67 & 0.33 & & 0.67 & & 0.67 \\
\hline 40 Improvements & - & - & 17 & 5 & 0.0122 & 34 & 20 & 0.0092 & & 0 & 0.33 & 0.33 & 0.33 & 0.33 & & & & \\
\hline 41 System Obsolescence & & - - & 2 & 2 & 0.0007 & 18 & 12 & 0.0042 & & 0 & 0.33 & 0.33 & 0.33 & 0.33 & & & & \\
\hline 42 System Quality & 4 & 40.0100 & 32 & 7 & 0.0244 & 32 & 17 & 0.0059 & & 0.33 & 0.33 & 0.33 & 0.33 & 0.33 & & & & \\
\hline 43 System Security Perception & 7 & 40.0218 & 23 & 8 & 0.0282 & 115 & 30 & 0.0251 & & 0.33 & 0.33 & 0.33 & 0.33 & 0.33 & & & & \\
\hline 44 Technology costs \& Budget & 3 & 30.0073 & 27 & 8 & 0.0310 & 116 & 36 & 0.0373 & & 0.33 & 0.33 & 0.33 & 0.33 & 0.33 & & & & \\
\hline 45 Technology Infrastructure & 10 & 60.0326 & 48 & 15 & 0.0429 & 72 & 26 & 0.0269 & & 0.33 & 0.67 & 0.33 & 0.67 & 0.33 & & 0.67 & & 0.67 \\
\hline 46 Technology Maturity \& Awareness & 6 & 30.0151 & 34 & 6 & 0.0340 & 48 & 25 & 0.0154 & & 0.33 & 0.33 & 0.33 & 0.33 & 0.33 & & & & \\
\hline 47 Timeframes & 4 & 40.0140 & 4 & 1 & 0.0042 & 68 & 33 & 0.0255 & & 0.33 & 0.33 & 0.33 & 0.33 & 0.33 & & & & \\
\hline 48 Trust \& Leadership Governance & 5 & 30.0130 & 25 & 12 & 0.0342 & 162 & 45 & 0.0554 & & 0.33 & 0.33 & 0.67 & 0.67 & 0.33 & & & 0.67 & 0.67 \\
\hline 49 Usage Behaviour and Use & 201 & $15 \quad 0.0627$ & & & & 85 & 31 & 0.0445 & & 0.67 & 0 & 0.67 & 0.67 & 0.67 & 0.67 & & & 0.67 \\
\hline 50 User Satisfaction & 10 & 80.0361 & & & - & 34 & 16 & 0.0099 & & 0.33 & 0 & 0.33 & 0.33 & 0.33 & & & & \\
\hline
\end{tabular}

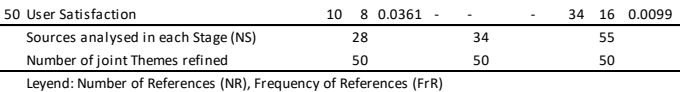

leyend: Number of References (NR), Frequency of References (FrR)

The three anchor points can define a set between the three stages: "High Level of References" (indicated by relationship scored 1), "No references" at all (relationship scored 0 ), and a crossover point (a probable relationship scored 0.5). However, between the extremes of the full level of references and non-level of references, a set can have fine-grained relationship levels of references, where the fuzzy score can take any value between zero and one, for example, ranging from four level sets $(0,0.33$, 0.67 , and 1). Cases on various sides of the crossover point per stage can be qualitatively different, while cases differing from the FrR in the set on the same stage of the crossover point may vary in the degree of relevance for a complete set [12] (see Table 1, Section 1 columns). 
Based on Legewie [5] and Ragin [12] suggestion, an fs/QCA applied a score to standardize ranges can take any value between 0 and 1 . Thus, for a more fine-grained relationship, the cases can be normalized in four-level sets $0,0.33,0.67$, and 1 , in relation with FrR of each theme, obtained from the three stages of the initial study (see Table 1). Table 2 (below) shows how the ranges are used. The scores were normalized and given a relevant fuzzy score.

Table 2. Normalized scores [15]

\begin{tabular}{|c|c|l|}
\hline FrR Range obtained from NVivo & fs/QCA Score & \multicolumn{1}{c|}{ Measure } \\
\hline 0 & 0 & No References \\
\hline 0.001 to 0.0402 & 0.33 & Low-Medium Level of References \\
\hline 0.0403 to 0.0803 & 0.67 & Medium-High Level of References \\
\hline 0.0804 to 0.1205 & 1 & High Level of References \\
\hline
\end{tabular}

\subsection{The consistency of the fuzzy score range}

To justify the sensitivity of the cutoff point, the researchers discussed consistency and the coverage of the fuzzy score range. For example, Ragin [12] states that combinations of conditions in which all cases are considered to relate regarding sufficiency and necessity are extremely rare. It is normal to expect that cases should differ somewhat from expected generalized patterns. For reasons of fit, therefore, it is essential to assess how strong cases match in different sets [5].

Furthermore, the outcome, evidencing computing consistency and resembling the idea of significance in statistical models, involves a degree of measurement of the necessity or sufficiency condition. In turn, this demonstrates causal conditions through the combination of conditions. Thus, the fs/QCA software computes consistency of the fuzzy scores' ranges used. The value range " 0 " indicates no consistency and "1" indicates perfect consistency, providing a measure of empirical relevance. This range of measurements is analogous to the variance contribution of a variable in a statistical model [12].

\section{The Refined Themes Selection Using $f s / Q C A$}

\subsection{Criteria for selecting the $f \mathrm{~s} / \mathrm{QCA}$ results}

Definitions stated concerning QCA were mostly textually taken from our previous published partial results Solorzano et al. [15], which helps to better explain terminologies for the fs/QCA process and fs/QCA software application used. The definitions used are determined as follows.

Case/s: the set(s) representing official concepts, used as part of a the qualitative analysis, as previously discussed ([16], [17], [18], [19], [20] as cited in Legewie [5]). 50 themes emerged from the first part of the research. Each theme is called a case (referred to as "case ID" in the software used).

Scoring criteria: The cases that scored between 0.67 or 1 for each of the conditions namely, necessity or sufficiency, were considered relevant to the study. The 
themes that obtained the highest frequency were selected for further analysis. These themes are also considered to be significant to all stages or within a stage themselves [15].

Necessity condition: Is applied to a determined set of themes (labeled A-themes) essential for outcome $\mathrm{Y}$ (referring to the candidate drivers of SISA), if $\mathrm{Y}$ is not achievable without the inclusion of A-themes. In all of the cases, outcome Y links the presence of the A-themes' condition [5]. The themes accomplishing this condition are determined as necessary for the results. These are identified as the "necessity condition" of determined outcomes [15].

Sufficiency condition: Defines a cluster of themes (A-themes) or the grouping of other themes (X-themes) enough for achieving Y (candidate drivers of SISA). Y will continually increase because of A-themes' presence. Other conditions, besides Athemes, can influence Y's outcomes. Such conditions indicate a causal relationship between A-Themes and outcome Y [5]. This condition is referred to as the "sufficiency condition" for the result [15].

INUS condition: Is a single condition of Z-themes. In itself, not necessary or sufficient but can group with other conditions sufficient for the outcome Y (candidate drivers of SISA) $[5,15]$.

Causal recipes: Are conditions that use Boolean algebra to formally analyze to what degree condition(s) are necessary or sufficient for an outcome [5, 15].

Table 3 shows the formulas for the Causal Recipes used and computed in the fs/QCA software. The intention is to cover Sufficiency, Necessity and Inus conditions that can be obtained.

\section{Discussion and Results}

\subsection{The $f$ s/QCA computerized process and analysis}

$F_{S}$ /QCA software was used to differentiate the Sufficiency, Necessity and possible Inus conditions, for the initially 50 identified themes. The spreadsheet with the original calculated FrR was uploaded to automatically convert the frequencies to the proposed normalized fuzzy scores (see Table 2). The results obtained by computing all the causal recipes for the 50 themes concerning the three previous stage processes, were stored in a different table (see Table 1 Section 2). Different proposed recipes, evidencing necessity or sufficiency aspects of the relationship, were calculated and carefully examined.

During the $f_{S}$ /QCA process the causal recipe, named 'Selected Themes with Higher Relevance' (STHR), formulated as a combination of stages 1, 2, and 3 in the analysis process (see Table 3), was identified as the conditions that gained the best result through the fit. This recipe accomplishes the necessity of including Medium-high and High themes obtained as outcomes of Stage 3 (S3), which are also emergent themes from Stage 2 (S2) and S3, and Stage 1 (S1) (see Fig 2).

In the end, six themes were obtained as the most relevant. The most significant theme to all stages in the study case was also identified (see the last figure on Table 3 
and the joining point in Fig 2). It was done by computing the 'Level of Reference joining the three themes' (LRAND) recipe, applying a simple logic of _AND_combination of $\mathrm{S} 1, \mathrm{~S} 2$, and $\mathrm{S} 3$. This recipe was used to measure the theme's reference level as part of the stage in the overall process (see the formula in Table 3).

Table 3. Causal Recipies for the initial themes set identified as possible SISA drivers

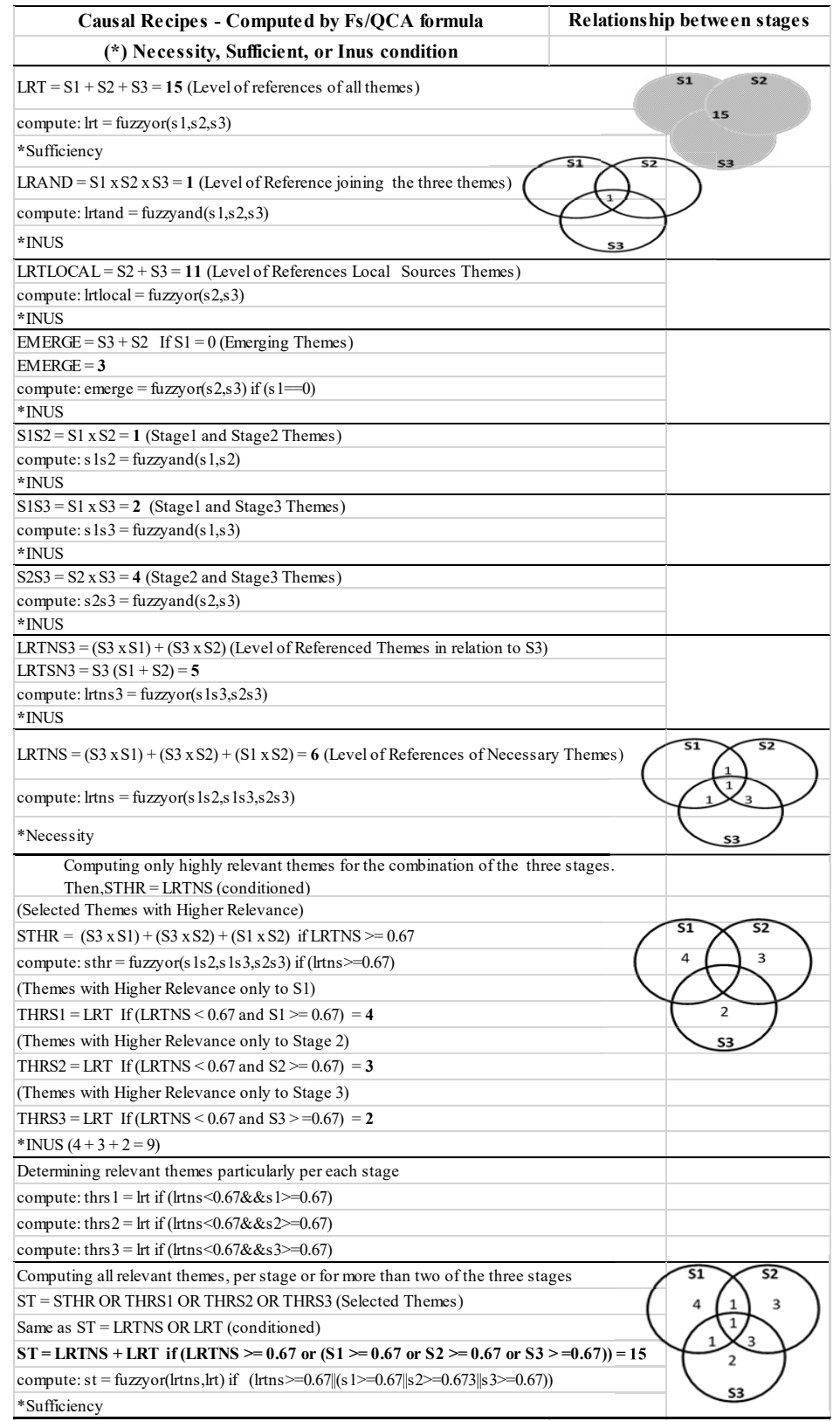




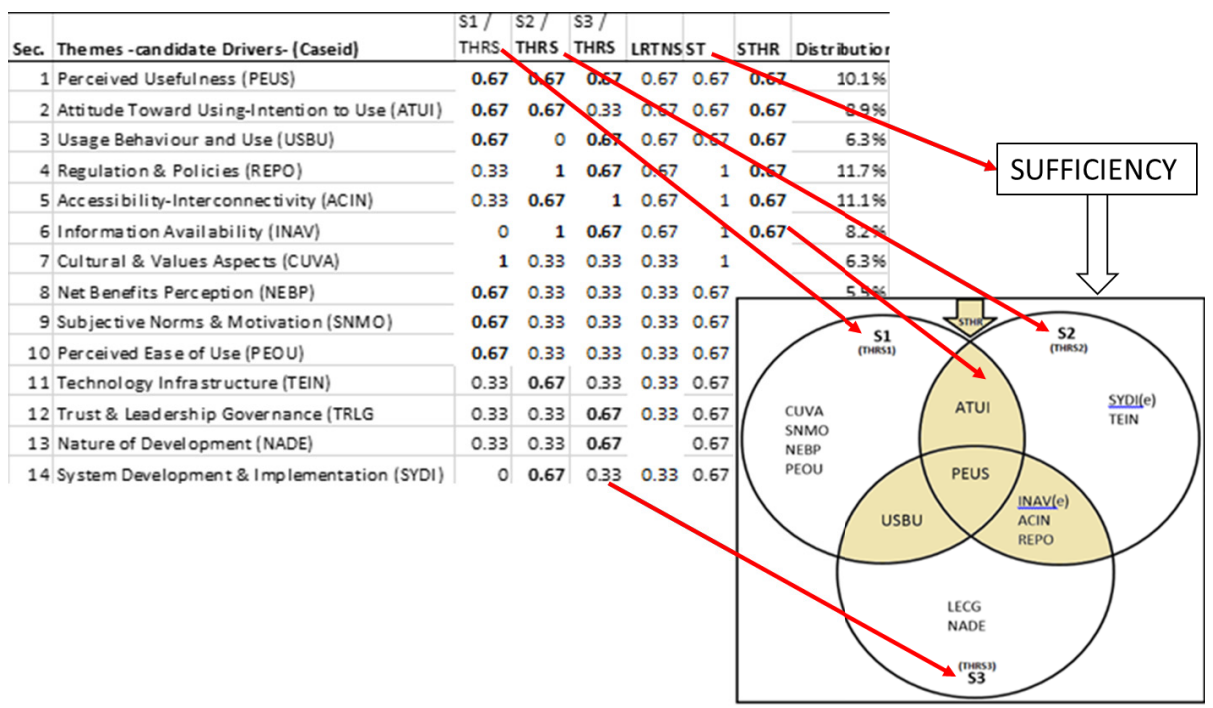

Fig. 2. Structure of selected themes as candidate SISA in LAT drivers

The six themes achieved the necessary conditions by the 'Level of References of Necessary Themes' (LRTNS) causal recipe, with a standard deviation of 0.1495882 (see Table 4). These themes in the STHR recipe (as higher selected themes of LRTNS) scoring 1 or 0.67 (using the $f_{s} /$ QCA scale) were analyzed, resulting in a low standard deviation (9.93411E-09).

Table 4. The initial themes set identified as possible SISA drivers

\begin{tabular}{lrrrrrr}
\hline Variable & \multicolumn{1}{c}{ Mean } & \multicolumn{1}{c}{ Std. Dev. } & Minimum & Maximum & $\begin{array}{c}\text { N } \\
\text { Cases }\end{array}$ & Missing \\
\hline s1 & 0.338 & 0.1950179 & 0 & 1 & 50 & 0 \\
s2 & 0.3184 & 0.2404775 & 0 & 1 & 50 & 0 \\
s3 & 0.3644 & 0.1679305 & 0 & 1 & 50 & 0 \\
Irt & 0.4584 & 0.2117958 & 0.33 & 1 & 50 & 0 \\
Irtand & 0.218 & 0.1702116 & 0 & 0.67 & 50 & 0 \\
Irtlocal & 0.4048 & 0.2153345 & 0 & 1 & 50 & 0 \\
emerge & 0.522857 & 0.244874 & 0.33 & 1 & 7 & 43 \\
s1s2 & 0.2248 & 0.181000 & 0 & 0.67 & 50 & 0 \\
s1s3 & 0.2776 & 0.1538124 & 0 & 0.67 & 50 & 0 \\
s2s3 & 0.278 & 0.1807761 & 0 & 0.67 & 50 & 0 \\
Irtns3 & 0.3376 & 0.1421768 & 0 & 0.67 & 50 & 0 \\
Irtns & 0.3444 & 0.1495882 & 0 & 0.67 & 50 & 0 \\
sthr & 0.67 & $9.93411 \mathrm{E}-09$ & 0.67 & 0.67 & 6 & 44 \\
sthrs1 & 0.7525 & 0.1428942 & 0.67 & 1 & 4 & 46 \\
sthrs2 & 0.67 & $9.93411 \mathrm{E}-09$ & 0.67 & 0.67 & 3 & 47 \\
sthrs3 & 0.67 & not computed & 0.67 & 0.67 & 2 & 48 \\
st & 0.758 & 0.1459315 & 0.67 & 1 & 14 & 36 \\
\hline
\end{tabular}




\subsection{The $f s / \mathrm{QCA}$ results}

While the STHR explains the necessary condition (Necessity condition) to identify the critical themes for combined stages, it does not reflect the themes determined as highly significant at any specific stage. Such inclusions are better explained in the Selected Themes (ST) recipe as a "Sufficiency condition" which gives a response to the QCA research question (see Table 3). Initially, 15 themes emerged from the ST recipe application (Table 1, last column), which included the amalgamation of the "Necessity condition" in STHR, and the "Inus conditions" of THRS1, THRS2, and THRS3 (see Table 3). Even though the ST recipe outcomes include the same quantity of themes as the LRT recipe which also allows identifying themes relevant to each of the stages at the same time, ST was singled out due to a lower standard deviation (0.14593) concerning LRT (see Table 4). ST also reinforces the significance of the connection between the themes and the stages of previous phases of this research.

From the computing results, 15 selected themes were obtained. Acronyms to identify each selected theme also were used (see Table 1 section 2). However, the content, concept, meaning, and opinions obtained from the sources in relation to selected themes were closely re-examined. Thus, it was, from the additional content analysis, that the themes named Intellectual Properties \& Software Rights and Regulations \& Policies are both defined as rules of law related to IS/ICT in the context of the current research. Therefore, they were regrouped within one theme as Regulations \& Policies without affecting the results of the recipes ST and STHR (see Table embedded in Fig 2). In the end, a final selection of 14 Themes as drivers of SISA in PEOs remains.

\section{Discussion of the Outcomes}

\subsection{The relationship relevance among the selected themes}

The 14 themes obtained with a higher level of relevance from the fs/QCA technique and their relationship within the three stages, were determined as a "Sufficiency condition" to answer the research question. In the end, six themes, selected by the acronyms - ACIN, REPO, INAV, PEUS, ATUI, and USBU — were identified as the most relevant themes, determined as the "Necessity condition" for SISA outcomes (see Fig 2). From the selected themes, PEUS was determined as the principal driver mentioned by all the sources. Finally, eight remaining themes-CUVA, NADE, TRLG, TEIN, NEBP, PEOU, SNMO, and SYDI- were identified as highly important, but only in one of the three stages at a time. These were recognized as "Inus conditions" accomplished (see Fig 1 [Field]). The obtained results were then anticipated as the sufficiency condition, represented by the ST recipe, and confirmed with the STHR recipe. The 14 themes obtained are then proposed as the utmost prominent candidate drivers of SISA in public LAT organizational contexts (see table embedded in Fig 2. 


\subsection{Clustering the themes for results}

To explore these themes further and to examine their influence as candidate drivers of SISA in LAT, we clustered them through related characteristics. The Control Characteristics group were determined based on existing literature and theories previously analyzed. Thus, the selected themes were examined and reorganized into groups; related to Subjective Aspects, Technological Aspects, and Public Aspects. We kept consistent with the organization undertaken in previous stages in which these themes were identified, or they emerged and were clustered according to their similarity (see Table 5).

Table 5. The selected themes as SISA drivers clustered by categories

\begin{tabular}{lcc}
\hline $\begin{array}{l}\text { Distribution by Categorie } \\
\text { Themes -candidate Drivers- (Caseid) }\end{array}$ & $\begin{array}{c}\text { fs QCA } \\
\text { Result (ST) }\end{array}$ & $\begin{array}{l}\text { Frequency } \\
\text { Distribution }\end{array}$ \\
\hline Subjective Aspects & & $41 \%$ \\
Attitude Toward Using-Intention to Use (ATUI) & $0.679 \%$ & \\
Net Benefits Perception (NEBP) & $0.676 \%$ & \\
Perceived Ease of Use (PEOU) & $0.675 \%$ \\
Perceived Usefulness (PEUS) & $0.6710 \%$ \\
Subjective Norms \& Motivation (SNMO) & $0.675 \%$ \\
Usage Behaviour and Use (USBU) & $0.676 \%$ & $35 \%$ \\
\hline Technological Aspects & & \\
Accessibility-Interconnectivity (ACIN) & $111 \%$ \\
Information Availability (INAV) & $18 \%$ \\
Nature of Development (NADE) & $0.675 \%$ \\
System Development \& Implementation (SYDI) & $0.675 \%$ \\
Technology Infrastructure (TEIN) & $0.676 \%$ \\
\hline Public Aspects & & \\
Cultural \& Values Aspects (CUVA) & $16 \%$ \\
Regulation \& Policies (REPO) & $112 \%$ \\
Trust \& Leadership Governance (TRLG & $0.676 \%$ \\
\hline
\end{tabular}

In the group containing themes with characteristics related to Subjective Aspects, six of them were identified as highly significant based on the $f_{s} / \mathrm{QCA}$ process. This group was determined with a distribution of $41 \%$ over the $100 \%$ calculated from the set of drivers selected (see Table 5 and Table 3 ). Perceived Usefulness (named with the acronym PEUS) was the only theme evidencing high significance in the three previous stages of the current study (see also Fig 2). In Technological Aspects, four themes were selected from this group, with a frequency of distribution of $36 \%$ over $100 \%$ (see Fig 3): In this group, we highlight that INAV and SYDI, are emerging themes from local sources (identified in S2 and S3). Emerging means that these themes do not have been proposed as drivers of IS adoption in the review of existing theories. In Public Aspects cluster, three themes were identified as relevant with 24\% 
over 100\% (see Fig 3). Regulations \& Policies (named with the acronym REPO) was identified as highly significant in S2 and S3 but also mentioned in S1.

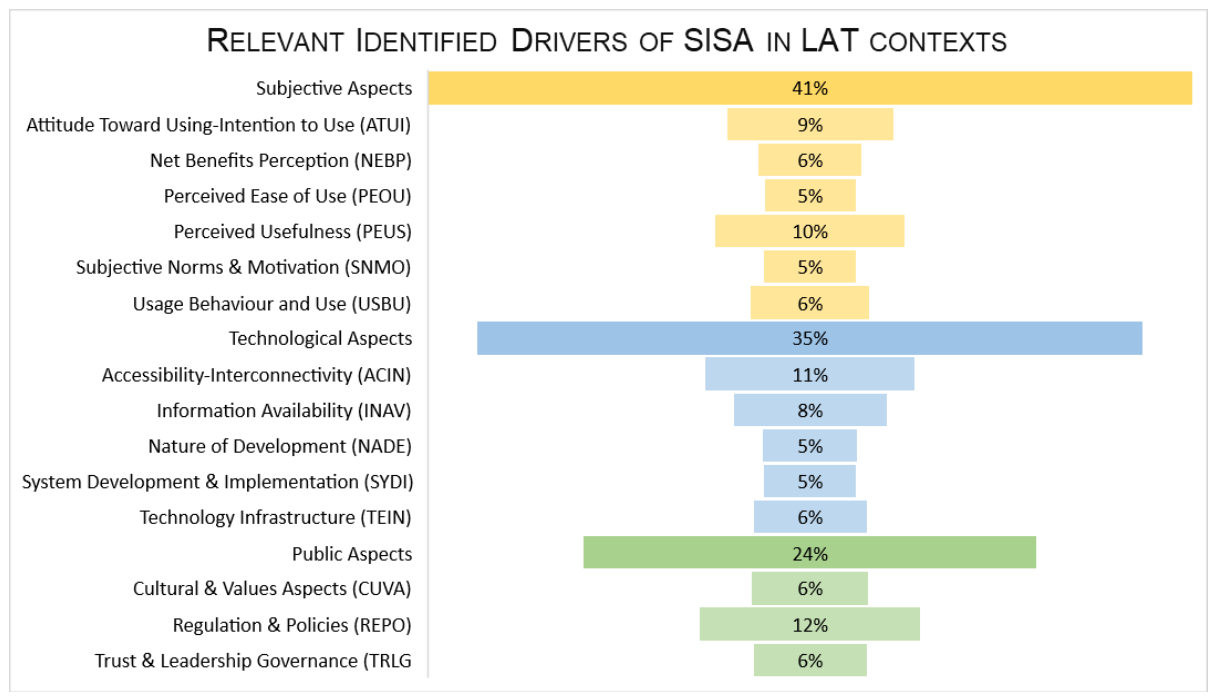

Fig. 3. SISA in LAT selected themes structure

In the end, from these clustering process, we obtained an organizational structure to grouping the selected themes for further analysis of their relationship as drivers affecting SISA in PEOs (see Table 5 Fig. 3).

\section{Summary and Conclusion}

In this paper using an $f_{S} /$ QCA case study to identify the candidate drivers of adoption in PEOs, we aim to explain the applicability of $f_{S} / \mathrm{QCA}$ in IS adoption studies. To this end, we apply fuzzy logic techniques to refine a set of identified drivers of adoption. The application of fuzzy logic in the selection process was made by using existing software packages. This approach helps to avoid ambiguities which are challenging to overcome in qualitative studies and provides clear and measurable outcomes. As a result, the application of QCA process using $f_{s} / \mathrm{QCA}$ to compute and normalize earlier outcomes, lead to the selection of 14 themes representing the candidate drivers of SISA in LAT regions. Mainly these were tested by accomplishing sufficiency conditions as drivers of adoption in PEOs. The possibility that the selected candidate drivers can be tested in other LAT contexts was anticipated. However further investigation should be done to check these assumptions further.

The results recognize the criteria used to select the relevance of the drivers chosen. The selection of relevant drivers includes the accomplishment of Inus, Necessity, and Sufficiency conditions enclosing the three previous stages of early phases of the current study. In the end, the process of using fuzzy logic on QCA involves the identification of relevant drivers from existing studies, local secondary data from LAT, and 
local primary data from PEOs. Therefore, we answered the stated research question "Which themes identified from existing IS/IT adoption theories, local secondary data, local experts/practitioners' opinion, are the candidate drivers affecting SISA in LAT organizational contexts?"

Future researchers should begin with the question of context as this study has. To start with the inquiry is important because the primary drivers point toward a different contextual frame than the one that dominates most adoption literature. That is, while traditional literature looks at the conditions from a traditionally highly developed technical culture (Silicon Valley or North American government institutions for example) most of the world is still developing their systems and challenges to adoption are very, very different for these nations. Future research should seek to explore the contextual variables that were emerging through analysis of both the local context and the traditional adoption models. A failure to do that will result in there being no real understanding of what the barriers to adoption are in emerging technological economies like Ecuador. Further, if researchers continue to apply models that were designed to measure adoption in economies that are entirely different, the results will continue to be less significant or even worse altogether spurious.

In conclusion, this study provides LAT stakeholders with a set of drivers that can be used to understand IS adoption within a specific context, namely in LAT regions. For future researchers, the findings will provide a conceptual context to explore future investigation to do comparative studies validating the selected drivers of IS in different organizations of LAT economies.

\section{$7 \quad$ Acknowledgement}

Our thanks to the ESPOL Polytechnic University, Escuela Superior Politécnica del Litoral, ESPOL, who sponsored the presentation of this work. We would also like to acknowledge the Griffith University in which the Ph.D. thesis containing the complete related investigation was undertaken, and to the British University in Egypt (BUE) for giving us the opportunity to promote this paper to be publish as an updated version of the conference paper presented in the $7^{\text {th }}$ ICSIE 2018, Cairo, Egypt.

\section{$8 \quad$ References}

[1] Ifinedo, P.: 'Drivers of E-Government Maturity in Two Developing Regions: Focus on Latin America and Sub-Saharan Africa', Journal of Information Systems and Technology Management, 2012, 9, (1), pp. 5-22 https://doi.org/10.4301/S1807-17752012000100001

[2] Gomez, R.: 'The Changing Field of ICTD: Growth and maturation of the field, 20002010', The Electronic Journal of Information Systems in Developing Countries, 2013, 58 https://doi.org/10.1002/j.1681-4835.2013.tb00408.x

[3] Wagemann, C., Buche, J., and Siewert, M.B.: 'QCA and business research: Work in progress or a consolidated agenda?', Journal of Business Research, 2016, 69, (7), pp. 25312540 https://doi.org/10.1016/j.jbusres.2015.10.010 
Paper-Applying QCA with Fuzzy Logic to Generate a Refined set of Factors for Information Systems...

[4] Viswanathan, M., Bergen, M., Dutta, S., and Childers, T.: 'Does a single response category in a scale completely capture a response?', Psychology and Marketing, 1996, 13, (5), pp. 457-479.https://doi.org/10.1002/(SICI)1520-6793(199608)13:5<457::AIDMAR2 $>3.0 . \mathrm{CO} ; 2-8$

[5] Legewie, N.: 'An Introduction to Applied Data Analysis with Qualitative Comparative Analysis,' in Editor (Ed.)^(Eds.): 'Book An Introduction to Applied Data Analysis with Qualitative Comparative Analysis' (2013, 2013-07-31 edn.), pp. 1-30

[6] Servant, F., and Jones, J.A.: 'Fuzzy fine-grained code-history analysis,' in Editor $(\text { Ed. })^{\wedge}($ Eds.): 'Book Fuzzy fine-grained code-history analysis' (IEEE Press, 2017, edn.), pp. 746-757 https://doi.org/10.1109/ICSE.2017.74

[7] Schneider, C.Q., and Wagemann, C.: 'Standards of Good Practice in Qualitative Comparative Analysis (QCA) and Fuzzy-Sets,' Comparative Sociology, 2010, 9, (3), pp. 397-418 https://doi.org/10.1163/156913210X12493538729793

[8] Beekhuyzen, J., Nielsen, S., and von Hellens, L.: 'The Nvivo looking glass: Seeing the data through the analysis,' in Editor $(E d .)^{\wedge}($ Eds.): 'Book The Nvivo looking glass: Seeing the data through the analysis' (2010, edn.), pp.

[9] Mingers, J.: 'Combining IS research methods: Towards a pluralist methodology,' Information systems research, 2001, 12, (3), pp. 240-259

[10] Mingers, J.: 'The paucity of multimethod research: a review of the information systems literature,' Information systems journal (Oxford, England), 2003, 13, (3), pp. 233-249

[11] Solorzano Alcivar, N., Sanzogni, L., and Houghton, L.: 'A Pluralistic Methodology for a Refined Selection of Drivers Influencing Information System Adoption in Public Organizations: the Case for Ecuador,' 2016

[12] Ragin, C.C.: 'Redesigning social inquiry: Fuzzy sets and beyond' (University of Chicago Press, 2008. 2008) https://doi.org/10.7208/chicago/9780226702797.001.0001

[13] Creswell, J.W.: 'Qualitative inquiry \& research design: Choosing among five approaches' (Sage, 2013. 2013)

[14] Charmaz, K., and Belgrave, L.: 'Qualitative interviewing and grounded theory analysis,' The SAGE handbook of interview research: The complexity of the craft, 2012, 2, pp. 347365 https://doi.org/10.4135/9781452218403.n25

[15] Alcivar, N.I.S., Sanzogni, L., and Houghton, L.: 'Fuzzy QCA applicability for a refined selection of drivers affecting IS adoption: The case for Ecuador', in Editor (Ed.)^(Eds.): 'Book Fuzzy QCA applicability for a refined selection of drivers affecting IS adoption: The case for Ecuador' (IEEE, 2016, edn.), pp. 1-6 https://doi.org/10.1109/LACCI.2016.7885695

[16] Blatter, J.: 'Ontological and epistemological foundations of causal-process tracing: Configurational thinking and timing,' ECPR Joint Sessions, Antwerpen, 2012, pp. 10-14

[17] George, A.L., and Bennett, A.: 'Case studies and theory development in the social sciences' (Mit Press, 2005. 2005)

[18] Gerring, J.: 'Case study research: principles and practices' (Cambridge University Press, 2006. 2006) https://doi.org/10.1017/CBO9780511803123

[19] Mahoney, J.: 'The logic of process tracing tests in the social sciences,' Sociological Methods \& Research, 2012, pp. 0049124112437709 https://doi.org/10.1177/0049124112437709

[20] Strauss, A.L., and Corbin, J.M.: 'Basics of qualitative research: techniques and procedures for developing grounded theory' (Sage Publications, 1998. 1998) 


\section{Authors}

Nayeth I. Solorzano Alcivar is Professor of the ESPOL Polytechnic University, Escuela Superior Politécnica del Litoral, ESPOL, (Escuela de Diseño y Comunicación Visual, EDCOM), Campus Gustavo Galindo Km. 30.5 Vía Perimetral, P.O. Box 0901-5863, Guayaquil, Ecuador. She also collaborated as an adjunct professor at the Griffith University, at Nathan Campus in Brisbane, Australia. She often works as Program Committee Member, Reviewer, and Webmaster for international conferences and Scientific Editors (LA-CCI, TIC-EC, AIS, IGI Global). She is the Executive Director of ÑAWI a Scientific Magazine, EDCOM, ESPOL.

Louis Sanzogni is a member of Faculty at Griffith University in Brisbane Australia where he currently lectures in Management and Management Information System. His research interests are in the areas of Diffusion of Innovation and Technology Adoption. In his more recent publications, Dr. Sanzogni explored the effects of user perceptions on the adoption of innovations proposing some successful variations in pre-established as well as newly developed adoption models.

Luke Houghton is a Senior Lecturer in Information Systems and Management in the Department of International Business and Asian Studies. He is also a senior editor of Information Technology and People.

Article submitted 09 November 2018. Resubmitted 07 January 2019. Final acceptance 15 January 2019. Final version published as submitted by the authors. 